\title{
Currículo, experimento e experiência: contribuições da Educação em Ciências
}

\author{
Curriculum, experiment and experience: Science Education contributions
}

\section{Currículo, experimento y experiencia: contribuciones de la Educación en Ciencias}

\author{
JOSÉ LUÍs SCHIFINO FERRARO*
}

\begin{abstract}
$\longrightarrow \nLeftarrow$
RESUMO

Ao tomar como ponto de partida a possibilidade da problematização para (res)significar elementos essenciais ao ensino das Ciências da Natureza, lança-se por sobre o currículo um olhar ético-estético que reforça a necessidade e o direito de o aluno experienciar sem desconsiderar a importância da experimentação na construção de conhecimentos específicos da área. Considerando a dualidade experiência/experimento, o trabalho que segue não pretende evidenciar a necessidade de sobreposição uma sobre outra, mas discuti-las para que se possa resgatar a dimensão de transformação inerente ao conceito de educação muito além da pura aplicabilidade e domínio da técnica.
\end{abstract}

Palavras-chave: Currículo. Ensino de Ciências. Experiência.

\begin{abstract}
Taking as a starting point the possibility of questioning for (re) define essential elements in Natural Science teaching, this work haul over the curriculum an ethical-aesthetical look that reinforces the need and the right of the students experience without disregarding the importance of experimentation on the construction of specific knowledge of the area. Considering the duality experience/experiment this work does not intended to highlight the need for some overlap between these two dimensions, but discuss them in an attempt to rescue the transformation dimension of the educational concept far beyond the pure applicability and technical domain.
\end{abstract}

Keywords: Curriculum. Science Education. Experience.

\section{RESUMEN}

Tomando como punto de partida la posibilidad de problematización para (res)significar elementos esenciales a la enseñanza de las Ciencias de la Naturaleza, la mirada que se vuelve sobre el currículo tiene una dimensión éticoestética y refuerza la necesidad y el derecho que él alumno tiene de experienciar sin desconsiderar la importancia de la experimentación para la construcción de conocimientos específicos en esta área. Considerando la dualidad experiencia/experimento, el trabajo que sigue no tiene pretensiones de evidenciar la sobreposición de una sobre otra, pero generar una discusión para que se pueda rescatar la dimensión de transformación del concepto de educación más allá de la pura aplicación y dominio de la técnica.

Palabras clave: Currículo. Educación en Ciencias. Experiencia.

\footnotetext{
* Doutor em Educação, professor da Faculdade de Biociências e dos Programas de Pós-Graduação em Educação (PPGEDU) e Educação em Ciências e Matemática (PPGEDUCEM) da Pontifícia Universidade Católica do Rio Grande do Sul (PUCRS), Porto Alegre, RS, Brasil. E-mail: <jose.luis@pucrs.br>.
} 


\section{INTRODUÇÃO}

Inúmeros artigos relacionados ao ensino de Ciências, resultantes de pesquisas na área, apontam a relevância da experimentação, relacionando-a a uma construção e compreensão mais satisfatória de conceitos relacionados a fenômenos científicos. A montagem de experimentos (suas formas de funcionamento, a repetição da experimentação, o levantamento de hipóteses a partir da observação da reprodução fenomenológica) reconstitui as etapas do método científico, que, principalmente a partir de Descartes (2009), tem conduzido os modos de se fazer ciência com reflexos diretos também sobre os modos de ensiná-la. Sob esse aspecto, a experimentação e a aplicação do método passam a ser elementos de uma (re)produção considerada essencial ao fazer ciência, seja no âmbito da pesquisa ou pedagógico.

Nesse sentido, e principalmente entre os séculos XVII e XIX, as ciências "duras", como a Biologia, a Física, a Química e a Matemática, passam a ser identificadas pelo rigor metodológico associado a um distanciamento e isolamento do objeto a ser estudado. Nesse movimento, a experiência passa a ser entendida como sinônimo de experimento.

A ciência moderna, a que se inicia em Bacon e alcança sua formulação mais elaborada em Descartes, desconfia da experiência. E trata de convertê-la em um elemento do método, isto é, do caminho seguro da ciência. A experiência já não é o meio desse saber que forma e transforma a vida dos homens em sua singularidade, mas o método da ciência objetiva, da ciência que se dá como tarefa à apropriação e o domínio do mundo. Aparece assim a idéia de uma ciência experimental. Mas aí a experiência se converteu em experimento, isto é, em uma etapa no caminho seguro e previsível da ciência. A experiência já não é o que nos acontece $\mathrm{e}$ o modo como lhe atribuímos ou não um sentido, mas o modo como o mundo nos mostra sua cara legível, a série de regularidades a partir das quais podemos conhecer a verdade do que são as coisas e dominá-las (LARROSA, 2002, p. 7).

Como herança dessa lógica de análise e conversão da experiência em experimento pela ciência moderna, no campo da Educação em Ciências, tem-se caminhado na mesma direção: uma prática docente reduzida unicamente à experimentação e ao método, o que conduz a uma falsa impressão de que a dimensão do experimento supre a da experiência.

Ainda como consequência dessa percepção, quando se trata de transpor o conhecimento científico ("puro") para o pedagógico, tem-se aceitado como realidade eficaz uma falsa sinonímia entre "instrução" - relacionada à experimentação à qual se refere - e "aprendizagem significativa". Circunscreve-se o "significado" à compreensão do funcionamento de experimentos que permite observá-los e interpretá-los com as lentes do método. Este, por sua vez, lança um olhar muito mais informativo sobre a aprendizagem do que propriamente considera a possibilidade de "experienciação" - das vivências de acontecimentos que poderiam culminar em (trans)formações do sujeito - a partir do fenômeno científico. Há, portanto, uma confusão estabelecida entre os termos experimentação e "experienciação".

É preciso destacar, primeiramente, que a experimentação e o método ocupam uma dimensão demasiadamente importante quando se trata de se ensinar Ciências. Myriam Krasilchik (1988, p. 56) contribui e insere histórica e objetivamente a dimensão metodológica:

Um aspecto enfatizado a partir da década de sessenta foi a importância do conhecimento e a capacidade de uso do método científico, compreendido como um processo racional de tomada de decisão, com base em dados e com critérios objetivos. A importância dada a aulas práticas que, tradicionalmente, originava-se de sua eficiência como forma de aquisição de informação dos chamados produtos da ciência, deriva, agora, do potencial educativo de repetição do processo usado pelos cientistas em seus laboratórios na busca de informações e descobertas.

É preciso ressaltar que não se trata de pregar uma abdicação do método e do experimento. Pelo contrário. Esse ensaio tem como pretensão redimensionar e ampliar a compreensão sobre a importância de se conceber uma Educação em Ciências contextualizada e constantemente (res)significada, calcada também no acontecimento da experiência.

Para tanto, ao discutir o tema, deve-se considerar a estruturação de um currículo que permita incluir junto à experimentação a ideia de "experienciação" na condução do processo de aprendizagem. O "experienciar" como condição que não intenta sobrepor-se ao experimentar, mas que somados os elementos, permita ir além nos processos educativos, neste caso, relacionados ao ensino de Ciências.

Com certeza, as linhas que seguem não inauguram essa discussão acerca da experiência, mas desejam lançar sobre o tema outro olhar - de reflexos éticoestéticos - emergente de aprendizagens verdadeiramente significativas que se somam à experimentação e ao método e permitem realizar/assumir novas/outras leituras e posturas diante das coisas do mundo.

\section{CURRÍCULO, EDUCAÇÃo, EXPERIMENTO E EXPERIÊNCIA}

Quando se trata de discutir o currículo e as temáticas que tocam a dimensão curricular, volta-se as atenções aos 
propósitos da escola. Basicamente, o currículo escolar está organizado para atender a aspectos relacionados à educação, à instrução e à socialização dos estudantes (PÉREZ-GÓMEZ, 2001). Nesse sentido, é possível estudar o currículo na perspectiva da governamentalidade (FOUCAULT, 2011), como dispositivo que regula e governa as relações na escola (PEREIRA; FERRARO, 2011) e que pode compreender em si desejos e intenções que se refletem em uma série de práticas escolares que emanam sobre o conceito de Educação.

Ao exercer sua função na instância do governamento, o currículo pode apresentar mecanismos, dispositivos, estratégias que permitam e auxiliem os professores na condução de sua própria conduta. É preciso considerar uma mudança de perspectiva quando se trata da organização logístico-metodológica - de planejamento pedagógico - para a condução das aulas de Ciências, além de sua própria concepção de educação para que se possa dar mais voz à experiência.

Para Jorge Larrosa (2002), ao conceito de Educação estão atreladas, basicamente, duas concepções. A primeira delas corresponde à Educação como sinônimo de instrução. Educar, nesse sentido, adquire um viés de resultado prático, pois resulta em domínio e aplicabilidade de conhecimentos e técnicas específicas, não refletindo nada além disso. Diferentemente da primeira, a outra concepção não inscreve o sentido de educar em uma dimensão técnica, mas conduz a uma compreensão maior em relação ao mundo que demanda um posicionamento ante as questões da vida cotidiana. Ampliar o conhecimento do mundo e estreitar as relações que se tem com ele resulta, naturalmente, em um engajamento político que permite realizar verdadeiros juízos de valor para que se possa avaliar o que, de fato, é preciso transformar.

Larrosa, a partir dessa distinção, conduz a discussão na direção da "experiência" e, exatamente a partir desse ponto, é que o propósito e a intenção desse ensaio começam a ser fundamentados. Porém, antes de um aprofundamento sobre o tema, é preciso retornar a questão da "aprendizagem significativa" diante de duas concepções de Educação as quais se fez referênica.

David Ausubel apresenta o termo/acontecimento "aprendizagem significativa" enquanto possibilidade de se apre(e)nder o conhecimento, também, a partir de uma dimensão psicológica. Aquilo que o sujeito traz consigo de suas experiências prévias se torna fundamental para uma série de aproximações que lhe permitem estabelecer relações com o novo (AUSUBEL, 1963; 1968). Segundo o dicionário Aurélio (2004), "significativo" deriva do substantivo "significado" e está relacionado, entre outras coisas, com "sentido".

Em assim sendo, a "aprendizagem significativa" seria uma aprendizagem com sentido. Mesmo assim, ainda seriam necessários alguns questionamentos. $\mathrm{O}$ que de fato faz sentido? Quando faz sentido? Como faz sentido? Como avaliar o sentido ante uma série de sujeitos distintos que estão sendo expostos ao contato de um tipo de conhecimento que informa da mesma maneira, ou seja, encontra-se homogeneizado, seja nos discursos dos professores, no caso de Ciências, ou em materiais didáticos elaborados como referência para a área?

$\mathrm{O}$ desafio está justamente aí. Sublevar a experiência - e distingui-la - em uma área onde a mesma se apresenta como sinônimo de experimento pode ser um dos pontos de transformação para a Educação em Ciências, a começar por novos desenhos e configurações curriculares. Um currículo que pudesse oportunizar e contemplar uma série de experiências desde sua programação (currículo programa) ou simplesmente dando mais voz à expressão dos sujeitos (currículo corte) contribuiria fortemente tanto para que os experimentos fossem tão bem mais compreendidos quanto para que esses sujeitos compreendessem a si mesmos na relação com o mundo. Os conceitos de currículo, programa e currículo corte (KROEFF, 2001) serão abordados mais adiante.

Dito isso, é fato que tais questões impelem a pensar a Educação em Ciências para além da dimensão do experimento e do método como simples reprodução no jogo da falseabilidade do argumento (POPPER, 2004). Na perspectiva da experiência como possibilidade de vivenciar, (res)significar e deformar, surge a possibilidade de serem delineadas estratégias de aproximação com o novo do conhecimento. Para tanto, é preciso (re)pensar o currículo das disciplinas de Biologia, Física, Química e Matemática, que, se de um lado necessitam de um alto poder de abstração dos alunos, por outro, encontra-os cada vez menos imbricados na relação com as coisas do mundo, em uma época que insiste em confundir educação com informação. Esse fato pode ser um dos agentes para a abdicação da experiência em nome da instrução, de um conhecimento "enlatado" e homogeneizado, considerado, talvez, "suficiente" à sobrevivência em uma sociedade que parece ter optado por uma educação puramente voltada a resultados, metas e objetivos. E que, além disso, assume em seu discurso determinados regimes de verdade (FOUCAULT, 1986) como absolutos ao desconsiderar outros saberes e experiências individuais. Eis o retrato da contemporaneidade.

É preciso ressaltar que o domínio da informação está longe de constituir-se como aprendizagem significativa. A informação como ação orientada no sentido professoraluno permite que o sujeito passivo da relação possa elaborar uma opinião sua, mas que - apesar de ser sua - não necessariamente foi vivenciada a ponto de que aquele que passa a emiti-la possa também considerar a opinião do outro. Segundo Larrosa $(2002 ; 2011)$, é esse 
movimento de informação-opinião (entre outras coisas) que mata a possibilidade de experiência. Parece não haver necessidade da experiência porque na contemporaneidade o tempo é exíguo e porque alguém já informa emitindo uma opinião que passa a ser reproduzida. Se forem tomadas como referência as instituições de ensino que vêm priorizando a instrução, o que menos se vê são escolas que investem na promoçāo da experiência que remete à vivência do fato, à análise do contexto, à aplicação no cotidiano, seja em termos práticos ou filosóficos. Como algo que eu aprendo pode transformar minha visão e meu comportamento para com o mundo?

A partir disso, Marcos Villela Pereira (2012) e Nadja Hermann (2006) apontam a importância da dimensão estética, da experiência relacionada ao processo de formação da subjetividade humana.

Os efeitos da experiência estética - os valores, os sentimentos, os gostos, os juízos, as representações, as categorias - são as modalidades das experiências que vão se modificando com a própria história, cujo núcleo é sempre essa estranha satisfação que resulta do reconhecimento da capacidade de construir, de produzir sentidos que, quando a gente experimenta, ao mesmo tempo está construindo e produzindo a gente mesmo (PEREIRA, 2012, p. 120).

O estético abandona um pouco de sua concepção inicial - que se limitava à contemplaçāo do belo - e passa a ser concebido como linha de fuga que contribui para a sustentação do sujeito.

A ficção auxilia a enfrentar as funções do cotidiano e assim a experiência estética torna-se um caso particular da experiência habitual. Para que tenhamos aqueles "raros momentos" de surpresa e inesperado que funcionam como descarga para o cotidiano e pelos quais produzimos novos sentidos, precisamos do contraponto da experiência habitual. A arte só pode funcionar como libertação das funções do cotidiano se permanecer a diferença entre arte e vida. Caso vivêssemos apenas da descarga estética sem o confronto da experiência habitual, a própria identidade do sujeito se dissolveria na ficção (HERMANN, 2006, p. 4).

A experiência estética conduz a um (re)pensar a prática cotidiana, e muitas vezes acaba modificando-a, resultando assim também numa mudança do ethos. Experiência que surge como possibilidade de novas formas de se lidar com as coisas do mundo, a dimensão ético-estética da própria experiência como agente de (trans)formação do sujeito. $\mathrm{O}$ que estaria muito mais alinhado com a segunda concepção de educação, como práxis e engajamento político, do que com a primeira puramente instrucional.
Com isso, a dimensão da experiência e a "experienciação", então, ficam diferenciadas do "experimento" e da "experimentação". Não que a realização de um experimento não possa se converter em experiência, mas a maneira como os professores as têm conduzido acaba por subverter essa possibilidade - a do experimento como experiência -, reduzindo-a a mera reprodução.

Essa experimentação das aulas de Ciências adquire um caráter muito mais informativo do que de fato possibilita a discussão em torno do fenômeno que está sendo estudado, ou ainda não resulta efetivamente em experiência pelo caráter preditivo do experimento. Em muitos casos, o resultado já é esperado. A experiência, por sua vez, não lida com a certeza da predição, mas com a incerteza do resultado. $\mathrm{O}$ experimento reproduzido em sala de aula, mesmo não dando certo, pode ser contado: "Deveria ter acontecido assim", "deveria ter mudado de cor", etc. Não que com o erro não se possam tirar aprendizagens significativas, pelo contrário, é o próprio erro que move a Ciência e mobiliza o conhecimento científico. Gaston Bachelard (1996) corrobora e cogita o experimento científico como possibilidade de experiência a partir da retificação de erros:

[...] a experiência <<aqui leia-se experimento $>>$ que não retifica nenhum erro, que é monotonamente verdadeira, sem discussão, para que serve? [...] falta-lhe precisamente esta perspectiva de erros retificados que caracteriza, a nosso ver, o pensamento científico (BACHELARD, 1996, p. 14).

A crítica desse ensaio é que a condução e a ênfase dada à Educaçāo em Ciências, a defesa da experimentação e da pesquisa em sala de aula, e o aluno como partícipe e protagonista de seu próprio aprendizado não atendem à necessidade da experiência. Em outras palavras, a experimentação como reprodução muitas vezes inquestionável - está longe da produção do "acontecimento experiência", pois traz o afastamento da (res)significação propiciada pela dimensão ético-estética.

Inegavelmente, a reprodução também possui sua importância. Mas, talvez, pelo fato de que se precise contemplar uma série de conteúdos mínimos em um ano, série ou ciclo da educação básica - fala-se em currículo programa (KROEFF, 2001) -, a pesquisa em sala de aula não consegue atingir uma dimensão ideal, permitindo ao aluno ir em busca do novo, de um desvendar de suas incertezas. Por outro lado, a palavra programa não se associa apenas a uma sequência de conteúdos (programáticos), mas também a uma série de execuções outras, programadas, que visam à eficiência, à logística de distribuição de indivíduos (em distintas atividades, classificações, séries, rankings), tornando-os responsáveis por afazeres específicos. 
A concepção moderna e disciplinar de sociedade utiliza a Educação como um dos instrumentos para garantir a integração, através da participação dos indivíduos iguais, em unidades pertencentes a uma totalidade. Esta Educação visa assegurar a cidadania, organizando uma espécie de programa, ordenado pelo currículo, que prepara para o exercício dos direitos e deveres. Tal concepção denota o currículo como um programa, que visa atingir resultados. O programa configura um roteiro de execuções, que se encontra associado às práticas disciplinares. Este roteiro objetiva um fim, através de um percurso calculado que busca um melhor desempenho. A disciplina faz-se necessária uma vez que, conforme Foucault, corresponde 'à arte das distribuições' dos indivíduos no espaço e no tempo, conformando uma técnica de poder 'capaz de compor forças para um aparelho eficiente' (KROEFF, 2001, p. 1).

A experiência, então, adquire maior sentido do que a experimentação, pois não se trata apenas de fazer uma leitura de uma situação específica sobre o que é o experimento. Ela envolve emoção, surpresa, estranhamento e desacomodação. $O$ sujeito que experiencia realiza inevitavelmente uma leitura global e mais intensa da realidade, aciona múltiplos mecanismos de percepção. Ele frui do acontecimento que o conduz a uma percepção volumosa que, ao mesmo tempo em que o corta, transborda por todos os lados, interpenetrando mecanismos sensoriais. Sente-se inquieto sobre a possibilidade das múltiplas composições do real, pois seus modos de existência se chocam com suas próprias possibilidades, apontando novos caminhos para compor sua vida.

Eis, então, a experiência como algo maior, mas nunca definitivo. A experiência como "algo que me passa". Assim Jorge Larrosa (2002) a define a partir de seu próprio conceito em diversas línguas. Algo que "me" passa e me (trans)forma, não necessariamente "nos" passa, visto que muitas coisas podem ocorrer e não causarem transformações. Larrosa situa a experiência como algo que acontece ao sujeito e que não é ou não faz parte dele.

A experiência é 'isso que me passa'. Vamos primeiro com esse isso. A experiência supõe, em primeiro lugar, um acontecimento ou, dito de outro modo, o passar de algo que não sou eu. E ‘algo que não sou eu' significa também algo que não depende de mim, que não é uma projeção de mim mesmo, que não é resultado de minhas palavras, nem de minhas ideias, nem de minhas representações, nem de meus sentimentos, nem de meus projetos, nem de minhas intenções, que não depende nem do meu saber, nem de meu poder, nem de minha vontade. 'Que não sou eu' significa que é 'outra coisa que eu', outra coisa do que aquilo que eu digo, do que aquilo que eu sei, do que aquilo que eu sinto, do que aquilo que eu penso, do que eu antecipo, do que eu posso, do que eu quero (LARROSA, 2011, p. 5).
A ideia de experienciar vai ao encontro de formar e transformar, por isso é algo que nunca acaba, pois o número de experiências significativas modifica incessantemente o sujeito da experiência que passa a alcançar coisas novas, inesperadas, e construir lógicas novas para a interpretação, intervenção e transformação do cotidiano. Ensinar Ciências a partir dessa lógica que é intrínseca à própria ciência - a da mudança, da metamorfose - parece fazer muito mais sentido e se aproxima muito mais da ideia de pesquisa em sala de aula.

Mas como o currículo poderia contemplar isso? $\mathrm{Na}$ tentativa de apontar um caminho para uma possível resposta, volta-se à ideia de currículo/programa, fazendo uso da metáfora proposta por Kroeff (2001), contrapondo-o com outra possibilidade curricular: a do currículo corte.

O currículo como programa pode ser comparado a uma rede. Porém, não como uma rede, no sentido apontado por Foucault, com suas descontinuidades, saltos, tensões e multiplicidades de cruzamentos de fluxos, onde ocorre a dissolução do Eu e da origem. Ao contrário, como uma espécie de rede de encanamento, com orientação predefinida, que organiza o escoamento dos fluxos-desejos: canalisa, barra, represa, reorienta. A rede de encanamento 'curricular' funciona como infra-estrutura básica do conhecimento com caráter funcional e produtivista. No entanto, o currículo concebido como corte, provoca a ruptura dos canos, fazendo jorrar, mesmo que momentaneamente, as linhas de fuga, as diferenças, as singularidades (KROEFF, 2001, p. 2).

A discussão sobre as dimensões do experimento e da experiência relacionadas à Educação em Ciências encontra em Felix Guattari e Gilles Deleuze uma possível acomodação. Ao se tomar como referência o conceito de currículo corte (KROEFF, 2001), aproxima-se das vertentes da experiência, pois são a voz e a história do sujeito que produzem os cortes, as interceptações necessárias que ocasionam novos fluxos e alternativas para o currículo. São possibilidades para a fuga, as linhas de fuga que desterritorializam elementos do currículo/ programa, deformando e transformando seus objetos e objetivos na perspectiva do devir.

Com isso, nessa perspectiva de devir, o próprio currículo extrapola suas próprias fronteiras, não sendo mais suficiente observá-lo como objeto de limites bem definidos, mas sim como possível discurso de multiplicidades. Clermont Gauthier, ao propor uma esquizoanálise do currículo, ressalta:

Podemos pensar num modo de conceber a idéia de objeto que não seja a habitual. Em geral, representamos o objeto como um ser, isto é, como alguma coisa 
de contornos limitados, como alguma coisa que existiria em si, na realidade, e da qual poderíamos fazer uma imagem. Tudo se passa como se pudéssemos determinar a identidade desse objeto, mostrar de uma maneira clara e inequivocamente aquilo que, legitimamente, faz parte dele e aquilo que não faz. Em suma, pensamos, em geral, que é possível apreender a essência do objeto. Trata-se sempre de escolher entre essas duas alternativas: ou esse objeto é 'isso' ou ele não é ‘isso’ (GAUTHIER, 2002, p. 144).

Deleuze e Guattari se fazem presentes exatamente porque, se ao currículo toca ser essa multiplicidade, sua plasticidade deve-se a inúmeros agenciamentos (arranjamentos) possíveis. Os currículos programa - as matrizes curriculares - quando saem do papel, quando seus conteúdos e práticas são colocados em movimento, abrem espaço para inúmeras performances, como aponta Gauthier (2002, p. 144).

[...] ao concebê-lo como uma multiplicidade de agenciamentos possíveis. Trocaríamos, assim, as competências pelas performances. Nesse caso, entretanto, não falaríamos mais de currículo, mas de agenciamentos curriculares. A forma, feita de contornos bem delimitados, cederia lugar aos diversos agenciamentos do objeto. Do objeto ou do ser do currículo passaríamos a um devir-x do currículo.

Os agenciamentos curriculares então continuariam uma função de dispositivo, mas seu funcionamento, agora, agiria no entrecruzamento de uma série de possibilidades. Recorre-se, então, às linhas do rizoma (DELEUZE; GUATTARI, 2007). Uma vez submersos na realidade dos agenciamentos curriculares, os indivíduos passam a ser subjetivados, surgindo como produtos da máquina do desejo curricular, mas não só: também como produto de seu próprio desejo. A partir disso, então, surge uma espécie de confronto do desejo. Se de um lado se tem o currículo como máquina desejante, por outro, tem-se também o desejo de indivíduos imbricados no processo educativo, indivíduos que desejam experienciar.

A discussão recai sobre o sujeito, sobre as formas de subjetivação, sobre como o sujeito está exposto à trama de fluxos subjetivantes movidos não apenas por seu próprio desejo, mas pelo desejo do outro. "O que desejam para mim não necessariamente é o que desejo. Vou me constituindo nessa luta", diz esse sujeito ao mesmo tempo em que pergunta: "Mas, quem é que deseja para mim e o que desejam para mim?".

Se o desejo é recalcado é porque toda posição de desejo, por menor que seja, pode pôr em questão a ordem estabelecida de uma sociedade: não que o desejo seja associal, ao contrário. Mas ele é perturbador; não há posição de máquina desejante que não leve setores sociais inteiros a explodir. Apesar do que pensam certos revolucionários, o desejo é, na sua essência, revolucionário - o desejo, não a festa! - e nenhuma sociedade pode suportar uma posição de desejo verdadeiro sem que suas estruturas de exploração, de sujeição e de hierarquia sejam comprometidas. Se uma sociedade se confunde com essas estruturas (hipótese divertida), então, sim, o desejo a ameaça essencialmente. Portanto, é de importância vital para uma sociedade reprimir o desejo, e mesmo achar algo melhor do que a repressão, para que até a repressão, a hierarquia, a exploração e a sujeição sejam desejadas. É lastimável ter de dizer coisas tão rudimentares: o desejo não ameaça a sociedade por ser desejo de fazer sexo com a mãe, mas por ser revolucionário (DELEUZE; GUATTARI, 2011, p. 158).

Foi exatamente a partir daí que se decidiu discutir sobre a dimensão da experimentação e da experienciação na Educação em Ciências. Nesse espaço entre os desejos de quem ensina e de quem aprende, vê-se constituído o campo das batalhas diárias dos processos educativos. É também aí que se torna imprescindível que a dimensão da experiência seja contemplada nesse movimento de fluxos no currículo, mesmo que o desejo seja um tanto perigoso em seu caráter revolucionário. Tanto quanto a educação em sua essência de transformação que se precisa urgentemente resgatar.

Para tanto, faz-se necessário perceber a discussão a partir de dois pontos básicos. O primeiro diz respeito à realidade de um sistema escolar fortemente comprometido e submetido aos desígnios da (re)produção de subjetividades capitalísticas. Segundo Kroeff (2001, p. 97):

A subjetividade capitalística consiste em um dos modos de subjetivação, capturando os componentes heterogêneos com o objetivo de tomá-los estereotipados através de sobrecodificações, isto é, da produção de significados reduzidos e limitados, a fim de garantir a reprodução da lógica dominante, da lógica do capital. Os territórios capitalísticos correspondem à referência e ao reconhecimento em um determinado padrão subjetividade fechada em si mesma, em identidades.

O segundo ponto básico - como extensão e desdobramento do primeiro -, por sua vez, trata das maneiras sobre como a escola contemporânea e seus professores têm assumido essa tarefa como profissão de fé, afastando-se cada vez mais do verdadeiro sentido da educação.

Tome-se, então, nesse panorama anunciado, os modos como se tem realizado nas escolas uma educação em Ciências. Antes de procurar a significação pela experiência, tem-se primado pela informação excessiva e incompleta de conceitos que muitas vezes se tornam abstratos, exatamente pelo fato de não pertencerem à realidade do aluno. $\mathrm{O}$ sentimento de pertença não se 
circunscreve apenas à questão originária, mas pelo fato de que determinadas coisas ou situações não são apresentadas para que o estudante possa de fato conhecê-las, explorálas, vivenciá-las. O ensino de Ciências nas escolas, quando ousa fazer algo (nem tão) diferente, estrutura-se em torno de atividades práticas. Como se disse em outro momento do texto, as práticas são necessárias, mas na maioria das vezes insuficientes, por não demandarem estratégias que conduzam antes da descoberta/resultado uma série de incertezas que são essenciais para a construção do método.

Tudo isso porque não há tempo. O currículo é visto como um caminho que deve ser percorrido seguindo um modelo fabril que visa - no final desse percurso - à eficiência (SILVA, 2013, p. 12). Ainda, nesse movimento, o currículo não pode se confundir com o aluno e o aluno não pode se confundir com o currículo. Há distanciamento entre o sujeito e o objeto curricular, corolário da informação encarada como conhecimento.

A escola, mais do que difundir conhecimentos que integram domínios de saber, difunde informação incompleta e útil (?) na lógica do resultado. Não se observa o interesse da descoberta sobre como a tecnologia funciona, ou sobre os processos que conduziram a ciência a desenvolver determinada tecnologia. Vive-se tempos em que os alunos desejam apenas consumir a tecnologia, assim como desejam consumir informação rapidamente. Não há real interesse pelo aprender, mas apenas em acumular a informação já com o anseio de devolvê-la em avaliações que simulam as provas dos concursos de acesso ao nível superior.

Ainda se tem tratado os alunos de maneira homogênea. Valoriza-se mais o ponto de corte da nota, a média. Desejase adequá-los a uma normalidade imposta pelo sistema. Não se trata apenas de normatizar para o disciplinamento, mas, além disso, também há uma normalização do que se considera essencial ao conhecimento e à sua inserção - demanda - no corpus social, na contemporaneidade. Segundo Foucault, "a disciplina classifica os elementos assim identificados em função de objetivos determinados" (FOUCAULT, 2008 ${ }^{\mathrm{a}}$, p. 75).

Aqui, cabe uma ressalva: as práticas que visam à normalização são de natureza discursiva. Em assim sendo, a existência de discurso empoderado regula e controla movimentos, ações, distribuições e acaba por pautar as estratégias e táticas pelas quais esse empoderamento se mantém numa espécie de retroalimentação. $\mathrm{O}$ poder é exercido sobre um discurso cuja finalidade é reforçar efeitos de poder (FOUCAULT, 1999).

A partir da perspectiva normalizadora, segundo a escola hoje, você pode conhecer todas as funções e partes de uma célula, detalhes da reprodução dos vegetais ou dos mecanismos da transmissão gênica, mas talvez você não esteja preparado para discutir aspectos sobre o uso de embriões na pesquisa, manipulação de células-tronco, sustentabilidade ou transgenia. E é exatamente isso que passa despercebido pela maioria dos alunos e de seus pais.

Nesse viés, pode-se afirmar que muitas são as questões que atravessam a discussão para uma Educação em Ciências com qualidade. $\mathrm{O}$ discurso do construtivismo no ensino de Ciências poderia pautar uma espécie de agenda positiva quando se trata de melhorar verdadeiramente aspectos relacionados à aprendizagem. Como toda construção é processo, deve-se pensar nos modos como se pode produzir em nossos alunos sensações que ao mesmo tempo os desacomodem e também os instiguem e os conduzam à reflexão. Para tanto, não se trata de "vencer conteúdos", mas de contextualizá-los, redimensioná-los para (res)significá-los a partir de uma realidade que é do estudante em sua relação com o mundo.

Ao invés disso, tem-se visto uma ação contrária por parte dos professores. O referido processo de construção é deixado de lado. Copia-se, reproduz-se apenas atividades de "sucesso" no sentido experimental. "Vamos ver se dá certo com essa turma", diz o professor que quer otimizar, além do próprio processo, o tempo que dispõe, servindose assim de uma receita, uma espécie de construtivismo enlatado. Recai-se, então, na discussão experimento vs experiência.

\section{O QUE LEGITIMA A ESCOLA QUE POUCO EXPERIÊNCIA? AINDA, ALGUMAS CONSIDERAÇÕES}

Ao longo do texto, intentou-se apresentar um contraponto sobre a relação experimento/experiência tomada, equivocadamente, como sinônimo. Durante o desenvolvimento do tema, algumas referências sobre o ensino de Ciências foram feitas, tendo em vista que nesse universo professores servem-se do experimento, muitas vezes sem perceber o quão maior é a dimensão do experienciar.

Há uma redução significativa da experiência em nome do experimento. Mas, além disso, deve-se, ainda, considerar que talvez o grande equívoco nesse sentido esteja no discurso das instituições de ensino formadoras de professores. Há certa lógica, se, na pauta dessa discussão, as relações de saber-poder forem envolvidas nas formações discursivas, tal como apresentadas por Foucault: um discurso qualquer, que legitime qualquer "verdade", encontra-se empoderado ao criar domínios que possam afirmar ou negar afirmações, dizer o que dentro de seus limites - funciona de forma verdadeira ou falsa (FOUCAULT, 2008').

Nesse sentido, observa-se a replicação da lógica que - mesmo reforçada por tal empoderamento - se 
engana ao enfatizar que a instrução pela informação e a experimentação sem contextualização são sinônimos de educação e aprendizagem significativa. Isso justifica a pergunta do título desta subseção: "O que legitima a escola que pouco experiencia?”. Em primeiro lugar, deve-se compreender o termo legitimação na perspectiva de uma autorização: de uma legitimação/autorização discursiva. A escola contemporânea parece estar autorizada, por algum tipo de poder, a confundir educação com instrução e toda a ênfase da experimentação - vide ensino de Ciências -, em experiência. Isso significa exatamente que determinados dispositivos de poder reforçam um imperativo no qual a norma é a instrução.

É preciso falar da escola que experimenta - e pouco experiencia - do ponto de vista da produção de um discurso em torno da instrução. Para tanto, o que vem a legitimar a escola contemporânea, mas de raízes fortemente modernas, são os sistemas, as táticas e as estratégias de poder que podem ser verificadas regulando práticas e as formas pelas quais a estrutura escolar atual se mantém praticamente inabalável. Exatamente sob esse viés, a escola se reconhece e se legitima como tal. Não como produtora de conhecimento, mas como "passadora" de informação.

Ao tentar apontar caminhos para (re)pensar essa discussão que não se inaugura aqui, ressalta-se que a formação das já referidas subjetividades capitalísticas e das máquinas sociais codificantes dos fluxos de desejo (DELEUZE; GUATTARI, 2011, p.188) tem reflexos sobre essa realidade. O sistema que reproduz - à luz do capitalismo -, como já discutido por Bourdieu e Passeron (2013), e a escola tal qual aparelho ideológico do Estado, como proposto por Althusser (1980), podem apontar um caminho possível para a compreensão da dinâmica, do funcionamento das instituições de ensino atuais.

Foucault $\left(2008^{\text {b }}\right.$, p. 154) aponta que na instituição da sociedade capitalista houve uma sujeição dos indivíduos a um consumo que tem por função a uniformização e a normalização. Se for considerado o fato de que para atender à demanda do consumo sempre é necessária uma produção maciça, tem-se um indício da guinada do que se entende por educar. Acaba-se sendo remetido a uma reprodução de mão dupla: sociedade reproduzindo a escola e escola reproduzindo a sociedade. A educação resumida à instrução, baseada na informação para que sujeitos ocupem postos, sejam inseridos em posições específicas do mercado de trabalho. Esse pode não ser "o", mas pelo menos se constitui em "um" motivo possível dos excessos em torno da experimentação.

A partir de tudo o que foi exposto, duas palavras resumem a vontade dessas linhas: provocar e desacomodar. Essas são as principais ideias que marcam a discussão do presente texto. Partindo de uma inquietação em torno do verdadeiro sentido, sobre a real noção de experiência e introduzindo elementos do ensino de Ciências, pretendeuse inscrever a demanda em uma dimensão curricular. O currículo como discurso e, portanto, campo de práticas discursivas pelo qual se estendem as relações de saberpoder. O currículo como discurso reflexo da escola.

Ao tentar relacionar esses elementos (experiência experimento - currículo - ensino de Ciências), desejou-se apenas abrir mais uma possibilidade para a retomada de um ensino verdadeiramente calcado na (trans)formação de sujeitos que são únicos. A valorização de informações ou saberes que não são fornecidos pela escola impede que a troca de conhecimentos singulares transforme-se em experiências plurais. Eles permanecem ali, adormecidos em cada estudante como experiência em potencial, mas pouco são mobilizados - principalmente quando se trata de observar as séries finais do ensino fundamental ou o ensino médio.

É preciso, então, repensar as relações de ensino a partir de múltiplas/outras possibilidades de aprendizagem. O papel do currículo - percebido como discurso da escola -, para tanto, é essencial. Repensá-lo a partir da dimensão da experiência pode ser o grande começo para que o discurso sobre os modos de ensinar e de aprender se modifiquem, ampliem-se em uma perspectiva vivencial, fazendo ressurgir pela experiência o principal propósito incutido na dimensão do educar: tornar o outro diferente, transformar.

\section{REFERÊNCIAS}

ALTHUSSER, Louis. Ideologia e aparelhos ideológicos do Estado. 3 ed. Lisboa: Editorial Presença, 1980.

AUSUBEL, D. P. The psychology of meaningful verbal learning. New York, Grune and Stratton, 1963.

Educational psychology: a cognitive view. New York, Holt, Rinehart and Winston, 1968.

BACHELARD, Gaston. A formação do espírito científico. Rio de Janeiro: Contraponto, 1996.

GAUTHIER, C. Esquizoanálise do currículo. Educação e Realidade, v. 27, n. 2, p. 143-156, 2002.

DELEUZE, Gilles; GUATTARI, Félix. Mil platôs. São Paulo: Editora 34, 2007. Vol. 1.

O anti-Édipo: capitalismo e esquizofrenia. São Paulo: Editora 34, 2011

DESCARTES, René. Discurso do método. Porto Alegre: LPM, 2009.

FERREIRA, A. B de H. Novo dicionário Aurélio da Língua Portuguesa. Editora Positivo, 2004.

FOUCAULT, Michel. Microfísica do poder. Rio de Janeiro, Graal, 1986.

1999. 
Segurança, território e população. São Paulo: Martins Fontes, 2008a.

Nascimento da biopolítica. São Paulo: Martins Fontes, 2008b.

A ordem do discurso. 17. ed. São Paulo: Edições Loyola, 2008c.

El gobierno de sí y de los otros. Buenos Aires: Fondo de Cultura Económica, 2011.

HERMANN, Nadja. Ética, estética e alteridade. Cultura e alteridade: confluências. Org. de Amarildo Trevisan, Elisete Tomazetti. Ijuí: Ed. Unijuí, 2006.

KRASILCHIK, Myriam. Ensino de ciências e a formação do cidadão. Em Aberto, Brasília, v. 7, n. 40, p. 55-60, 1988.

KROEF, Ada Beatriz Gallicchio. Currículo como máquina desejante. Reunião Anual da Anped, v. 24, p. 135-136, 2001.

Interceptando currículos: produzindo novas subjetividades. Educação \& Realidade, v. 26, n. 1, p. 93-114, 2001.

LARROSA, Jorge. Notas sobre a experiência e o saber de experiência. Revista Brasileira de Educação, v. 19, n. 1, 2002.
Experiência e alteridade em educação. Reflexão e Ação, v. 19, n. 2, p. 04-27, 2011.

PEREIRA, Marcos Villela; FERRARO, José Luís Schifino. Currículo e práticas de controle: o caso da gripe H1N1. Currículo sem Fronteiras, v. 11, n. 2, p. 134-146, 2011.

PEREIRA, Marcos Villela. Contribuições para entender a experiência estética. Revista Lusófona de Educação, n. 20 , p. 109-121, 2012.

PÉREZ GÓMEZ, Ángel Ignacio. A cultura escolar na sociedade neoliberal. Porto Alegre: Artmed, 2001.

POPPER, Karl R. A lógica da pesquisa científica. Rio de Janeiro: Cultrix, 2004.

SILVA, Tomaz Tadeu. Documentos de identidade: uma introdução às teorias do currículo. 3. ed. Belo Horizonte: Autêntica, 2013.

Recebido em 29-12-2015.

Aprovado em 29-12-2016. 